\title{
STABILITY OF GOLD STANDARD AND ITS SELECTED CONSEQUENCES: A COMMENT
}

\author{
DAVID HOWDEN*
}

\begin{abstract}
Kvasnička (2007) attempts to demonstrate that the gold standard may be an unlikely alternative for small economies to revert to. The crux of his argument deals with supply considerations that could prove fatal to a fledgling currency. An influx of gold from the world's existing gold stock, or its new production could prove to be a destabilising supply-side factor undermining the usability, and hence, adoption, of such a monetary system. We find fault with this for two main theoretical reasons. First, a distinction must be made between gold stock, and monetary gold. Second, the mechanism that creates monetary gold works as a natural break on unrestrained supply growth. Several additional clarifications are necessary as well, among them the role money supply plays in the trade cycle, and the casual relationship that exists between supply and price. Finally, an insightful comparison used linking monetary gold in a small economy to the use of cigarettes in a Second World War P.O.W. camp must be slightly altered to make a true comparison. Kvasnička does a great service to free-marketers by providing a theoretical attack on the choice of gold as a medium of exchange, however, in light of this paper's theoretical conclusions, the free-market defence of commodity money endures.
\end{abstract}

JEL Classification: B53 - Austrian Economics, E42 - Monetary Systems, E5 1 - Money Supply.

\section{I \\ INTRODUCTION}

Kvasnička (2007) ${ }^{1}$ argues that, although theoretically preferable, a return to the gold standard is practically improbable, if not impossible, at the present time. Although insightfully noting

\footnotetext{
* Universidad Rey Juan Carlos.

${ }^{1}$ All page numbers in parenthesis will refer to this paper, unless otherwise noted.
} 
that gold's past stability is irrelevant in assessing its future use as a money, his arguments have several specific points which must be clarified. This paper will look at five specific points in his analysis which are found lacking, as well as clarify some of the theoretical and practical issues concerning free-market monetary adoption.

These five points are:

1. Gold and gold money as being homogeneous, interchangeable commodities.

2. The stability from a supply shock being dependent on the size of the monetary stock.

3. The causal relationship that exists between gold's supply and demand, and its price.

4. Money supply fluctuations as being the cause of the trade cycle.

5. The comparison between a gold currency, and a cigarette currency in a P.O.W. camp.

The conclusion that a return to a gold-standard as unfeasible for small, independent countries is found wanting. In particular, a confusion over gold's role as a means of exchange seems to be the main contributor to the issue at hand. Gold as produced from raw ore in the ground is drastically different from gold used in monetary exchange. It is not the quantity of raw gold that should be assessed, but the quantity of monetary gold available to the public. Kvasnička further seems to opine that one quantity of money in the economy is more optimal than any other. This age old fallacy has been refuted numerous times, quoting Rothbard $(2004,766)$ «[w]e conclude that there is no such thing as "too little" or "too much" money, that, whatever the social money stock, the benefits of money are always utilized to the maximum extent» [Emphasis in original].

We shall conclude with a look at the true free-market, and Austrian, stance on the gold standard. 
II

FIVE CLARIFICATIONS

\section{The homogeneity of gold stock and gold currency}

Kvasnička (36) makes the assumption that gold for non-monetary uses will have an equal value to gold used for monetary purposes, "[w]e assume that gold in the non-monetary stock can be minted, and gold in the monetary stock can be melted down free of charge, i.e. gold can flow from monetary to non-monetary use and vice versa without restrictions, which equalizes its purchasing power in each of its uses.» ${ }^{2}$ This yields the conclusion that gold circulating as currency is interchangeable with that existing in a non-monetary form. However, it is foreseeable that a store would not accept a bracelet or necklace on par with a gold coin or a title deed to bullion issued from a credible source. The presentation of gold by itself is not credible, only that which has been presented or issued in a credible manner. Private companies of good repute could mint gold, stamp it so it is recognisable, or issue other reputable claim receipts in lieu of it. People, although nothing would stop them from accepting random gold jewelry, would be more apt to accept this «certified» gold more easily than the random pieces. ${ }^{3}$

As Menger (1892) would point out, the origin of money is the search for a liquid, mutually agreed upon medium of exchange. Liquidity is a key here as it reduces the bid/ask spread on prices, and hence reduces the costs associated with trade. The movement

2 Curiously, he (36) also states that gold used for «consumption» (i.e., computer circuits), «cannot be drawn back at a reasonable cost», and hence could not add to the gold stock. The question of whether gold used in one way can be recovered and reused is only a question of if it is profitable to do so, to make a distinction based on original use is misleading.

${ }^{3}$ Menger $(2007,316)$ would quote Julius Paulus on this matter of choosing a money that was separate from other goods, «[a] substance was selected whose public evaluation exempted is from fluctuations of the other commodities ... [a] mark (of its external value) was stamped upon its substance by society. Hence its exchange value is based, not on the substance itself, but upon its nominal value.» It can be seen that money, even gold money, is not valued solely as gold, but also as a medium of exchange. 
to a homogeneous measured unit different than regular raw gold stock is a natural occurrence in the market. A nominal system of weights or measures would come into practice, with an implicit, if not explicit voluntary agreement to use these in transactions. Gold may be chosen as a medium of exchange due to several important and unique properties; homogeneity, fungibility, indestructibility and rarity chief among them. But a medium of exchange is used as it is agreed upon and easily comparable. Gold is both of these as well, however, both these last two qualities can be increased through human transformation. Creating a common unit that is well known and distinct of raw gold would be the first step towards making a distinction between raw, untouched gold, and a monetary gold suitable for exchange. As Dowd $(1988,645)$ insightfully points out:

... mints would exist primarily to maximize [their] own profits, which could be generated in several ways. One is by offering competitive minting fees. Another is by developing a reputation for probity to reassure prospective customers that they would not be cheated. A third is by innovation: mints would experiment with coins of new denominations, alternative metals, and so on. [emphasis added]

Additionally, Garrison $(1992,62)$ points out, "there is an Austrian preference for gold as money, not due to its specific qualities, but also to the historic precedence that has been set over time of people preferring this as their standard» [emphasis added]. What Garrison fails to explicitly point out is that some of the qualities are not naturally given to gold, but are human added. The preference for gold as money is not the result of it being merely gold, but also due to the human labour that has made it into a suitable medium of exchange.

The point is not whether it is reasonable to expect individuals to accept any piece of gold equally, but to recognise that the search is not for any medium of exchange, but an agreed upon, commonly accepted medium of exchange. The costs involved with accepting any piece of gold (i.e., verification, weighing, etc) would make the use of a standardised medium an attractive 
alternative, and a natural progression for the market economy. It is a Keynesian error to view goods, even monetary goods, in terms of stocks of total supply or total demand. When viewed this way, monetary gold is distinct of the gold stock, and hence undeniably behaves in a way independent of it.

\section{Stability vis-à-vis supply shocks}

Kvasnička (33) opens with a comment linking gold's monetary stability with the size of its underlying monetary stock, "[t]he stability of the gold standard to shocks stemming from the world gold market depends critically on the size of the monetary stock of gold relative to the extent of these shocks.» Additionally, he later (41) notes, "[t]he monetary stock of gold acts like a cushion dampening the "gold" shocks: the higher it is, the more stable the price level is.» The implication here is that a small economy, with a small monetary gold stock, would face increased risk at the hands of a proportionately larger global gold supply.

A confusion arises here between absolute and relative stocks. In an absolute sense, it is true, if the existing supply is quite large relative to the new supply, the shock therefrom will be relatively minimal. The difference here is that Kvasnička compares the new global stock supply to the small existing monetary supply a country may have. However, the new supply does not just enter the country's economy freely, but affects the total global demand for gold. Hence, only a portion of that new supply will affect the country's gold stock. Hayek $(1943,211)$ had alluded to this fact stating, "[t]he much-discussed "vagaries" in the production of gold can easily be exaggerated. The great increases in the supply of gold in the past have in fact occurred when a prolonged scarcity has created a real need for them.» In light of this, supply increases can be attributed to large non-monetary demands which would utilise the gold in a non-monetary way keeping the two stocks (monetary and non-monetary) separate.

In fact, by Kvasnička's (50) own reckoning, the global supply of gold was 155,500 tonnes in 2005, and the new supply mined that same year was 2,520 tonnes. Hence, the new addition of 
stock amounted about a $1.5 \%$ increase. The same year «end user consumption ${ }^{4}$ was in fact, 3,727 tonnes in 2005, an amount far exceeding the amount of new supply. It can be seen that new global supply of gold should be of little immediate concern to a country with a small stock adopting the gold standard. When we compare this to some current fiat currency inflation rates, which are running up to the low teen percentages annually, it can be seen that this increase is quite tame in comparison. ${ }^{5}$

When we speak of flow and supply changes of money, we are concerned with the mechanism that sets this in motion, as well as the ease this can be achieved. Fiat currency's main deficiency is the removal of barriers to changing its supply indiscriminately Under political control, a fiat currency's supply is not so much determined by the needs or wants of the end-users, but on the whims of the politicians that control it. A gold currency, whose supply is necessarily constrained by the production thereof, and which is in turn dictated by the wants of users will not be indiscriminately produced, but will only be done to meet the needs of the public. Gold money supply would not be increased unless there was a demand for it through its end users, and this demand was expressed by a willingness to exchange something profitable to the gold producer for it.

When we look at a non-market institution controlling the supply of gold, it is instructive to think in terms of the common quantity theory of money. By surrendering the $Q$ portion of the equation to a non-market entity, we assume that they can determine it more optimally than the same market, or that it can gauge the relationships between $Q$ and the other variables objectively. In fact, as Garrison $(1996,199)$ points out «[central banking] lacks the ability to distinguish on a timely basis between movements in $\mathrm{V}$ and movements in $\mathrm{Q}$, it lacks the incentives to act in ways that would promote stability, and as a key player in

4 As quoted (51), the World Gold Council defines this as gold for production (jewelry, dental and industrial) use, as well as investment.

${ }^{5}$ For example, according to the Federal Reserve Bank of St. Louis (2008) the US Dollar MZM supply has been increasing at an annualised rate of over $10 \%$ for over two years. 
a political environment, it actually responds to incentives in ways that foster the instability.»

In the previous section it was demonstrated that the supply of monetary gold is distinct of gold stock. When supply fluctuations are assessed, it is important to distinguish between the growth of its value, and the growth of its quantity. The only control we directly hold over the supply of gold is of its quantity. The same holds true for fiat money. Comparing these two options, the supply of gold (in terms of quantity) is very inelastic compared to a fiat currency. Although its value may fluctuate at times, this is largely not directly controlled by humans the way that its supply is. When market actors require a money, they are concerned only with the value thereof, its ability to procure other goods and not the sheer quantity available. As this value is not directly controllable by us, the focus should shift to erasing non-market fluctuations in the quantity available. Using a medium such as a gold is one such method to achieve this goal.

\section{Casual relationships between supply and demand factors, and the price of gold}

Kvasnička (39) seems to confuse, or at least not fully explore, the interworkings of supply/demand conditions, and the price of gold, in particular, «any change of the "gold flows", i.e. of the supply ... or the demand for gold ... changes the long-run equilibrium - the price level changes permanently.» The relationship that exists between supply, demand and price is quite complex, and requires a further look.

New supply of gold is determined by the expected profit one can obtain from it. It can then be seen that supply will only increase if producers think that the price (possibly not realised until the future) will compensate them for their costs. However, when we say "producer», to whom is it we refer? For the analysis at hand, we are concerned with the effects on the monetary stock of gold. As was discussed in section II.1, the stock of monetary gold will likely be issued through a specific provider, or providers, who may or may not be an actual gold mine. The issuer will not 
issue further currency unless they think they can earn a profit from it. This profit will thus depend on what price they can obtain, and what their costs will be to create and issue this new gold.

It is unknown if monetary gold would be issued at par with gold, or at a premium. In fact, several companies competing with one another could have an assortment of prices for their monetary gold that depend on non-monetary factors, such as service, dependability, or trustworthiness. We do know that gold currency would not be issued below its market price as this would result in a loss to the issuer, and the purchaser would likely convert it to the higher valued gold alternative for an arbitrage profit. If it is indeterminate what the price of monetary gold would be vis-à-vis the bullion price, we can say that the costs associated will be positive. As was already discussed, gold currency would likely be homogenised in some way, divided into equal values, stamped for security and clarity, and so on, all actions that entail some value, and cost adding steps. If competition drives prices down on newly issued currency to near the gross market price, and costs entailed in making it fit for public use are positive, we can see profit margins may be slim. Indeed, profit margins over time will trend towards zero as new competition enters the market.

Demand for monetary gold will be dependant on the needs of the market. As has been shown before, any amount of money is the optimal amount of money for the market, so the case for additional gold demand is unclear. Whatever the case, supply of gold will be through a profit seeking intermediary with decreasing returns due to competition, and demand will depend on the freemarket needs of the market participants. This interplay will determine the price of monetary gold on the market in question.

\section{A general increase in the money supply as the cause of the trade cycle}

Kvasnička (42) makes a possibly inadvertent error in asserting «trade cycles are caused by changes of the aggregate price level...» From an Austrian perspective, there are three problems with 
this statement, and as Kvasnička is using the elimination or smoothing of the trade cycle as one criteria for judging a return to the gold standard's suitability, they are important ones to clarify.

The first is that it is not the change in the general price structure that is troublesome, but the relative price structure. Most Austrians maintain that a period of artificially cheap money (caused by an increased supply thereof) will create a relative decrease in the prices of goods in the higher orders. As people's preferences are constantly changing, the relative prices are also constantly changing. In fact, this implies that the general price level will also change, but this is a vague statement that sheds little insight. It is only by looking at the relative changes between the different orders of goods that one can begin to see the source of the trade cycle.

Second, it is not the relative price level change that is harmful in itself, but that change in the price level that is brought on by non-market forces. Most Austrians would maintain that it is government fiat credit expansion that artificially lowers interest rates and causes price level changes. An additional savings by the free-will of individuals will also affect the price levels, but in a healthy way that signals the real, underlying time preferences of the market participants. A government intervention can distort these signals, and thus create price changes inconsistent with what the free-market dictates, and requires.

Last, these relative price changes, even if caused by a nonmarket force, are not enough to cause the trade cycle on their own. Instead, entrepreneurs must be fooled into thinking that these changes reflect the underlying reality, and hence, change their actions in a way inconsistent with what the market really demands. Government interventions that limit the role entrepreneurs can serve in correcting, and thus compensating for these mispricings, can only serve to create distortions as entrepreneurs err in judgement concerning market demands. Alternatively, a lack of government transparency in its actions may inhibit entrepreneurs from seeing the true underlying source of the price changes. 


\section{The comparison between Radford (1945) and Kvasnička (2007)}

Lastly, we look at Kvasnička's comparison between Radford's (1945) look at the role cigarettes played in P.O.W. camps. The conclusion that he draws is not as straightforward as it seems, and may not even be relevant to the analysis at hand.

Radford looks into the deflationary/inflationary pressures caused by the supply and demand for cigarettes throughout the week. New supply would arrive on Monday mornings, sparking a sharp rise in the supply of cigarettes, the commonly accepted medium of exchange. Throughout the week, prices would generally deflate as the quantity of cigarettes declined, until the next supply shipment arrived. Kvasnička thus draws the conclusion that a similar result would occur in an economy with a small monetary gold stock when faced with a relatively large global supply increase. As was discussed in section II.1, the shock a global supply increase exerts on a set, relatively constant supply, such as gold stock, is overstated.

However, one additional difference should become clear. In the P.O.W. camp, for lack of a better medium, the prisoners were forced to use cigarettes. Generally, the medium of exchange is chosen for three reasons: homogeneity, indestructibility, and fungibility. Goods holding all three characteristics are quite rare in nature, giving rise to the propensity for gold to be naturally selected throughout history as the common exchange medium. In a P.O.W. camp of limited resources, the best monetary option available was cigarettes, which although quite fungible and homogeneous, are far from indestructible. In fact, as the supply was constantly smoked away, the monetary stock necessarily was reduced in a way that gold cannot be. Hence, it is natural to see a large inflation occurring on Monday morning (or prior in expectation).

Prices constantly change, and a gold-backed money would be no different. The primary concern in the origin of money however is not total elimination of price volatility, for this can never be absolutely achieved, but the reduction of spreads that add unnecessary costs to trade. Cigarettes in the P.O.W. camp were 
chosen in spite of their weekly volatility, due to the small spread afforded through their general acceptance, and hence, liquidity. In the same way, gold, or another market chosen commodity is chosen not necessarily for short-term price stability, but for the liquidity provided through the general demand that people have for it. ${ }^{6}$

An economy based on a gold-backed currency may not see total price stability, in fact given consumers' constantly changing preferences this is not even an option. But the key point here is that this apparent price instability will not be caused by nonmarket supply factors, as is the possible case with fiat monies, but due to the free-choice of market participants. In an economy using gold as the currency, monetary supply would remain relatively constant, seeing no continual decrease due to the existing stock being consumed. This continual barrage of supplyinduced inflationary pressure will be eliminated accordingly. Keynes' maxim may have been that «in the long-run we are all dead», but an individual must choose a store of value to preserve their wealth until that time, and possibly longer. The long-term preservation of wealth is one of the factors that has afforded gold this prominent role throughout history.

\section{III THE ROLES OF MONEY}

Kvasnička assesses the suitability of gold in terms of its stability. When viewing a currency's stability, this must be done in two ways, reflecting the two functions money serves. First is the monetary function as a medium of exchange. Stability in this case

\footnotetext{
${ }^{6}$ Instead of contrasting the camp's cigarettes with gold stock, the true contrast would between gold production and tobacco production. Hence, it is easy to see that it is not the general increase in tobacco production that affected the camp, but only that of cigarettes, and by extension, it is not total gold production that affects a gold monetary stock, but only monetary gold production. Additionally, an important distinction is seen by way of the fact cigarette users within the camp did not have to purchase the cigarettes in the strict sense, which differs from how free-market actors would obtain monetary gold.
} 
is short-term focused. Second, money must serve as a long-term store of value.

Any good can only be viewed relative to a possible alternative. As Hülsmann $(2003,41)$ points out, it would be "pointless to argue that monetary laissez-faire was deficient from some absolute point of view, if we lacked a better alternative system that we could use in its place. The relevant consideration is how the free-market production of money compares to other regimes.» We will now assess each of the roles money serves in light of this statement.

\section{Monetary gold as a medium of exchange}

Given the five earlier comments, what is the relationship between global gold supply, and the demands of a small economy? We have seen that the link between gold currency, and gold stock is not exact. Gold would undergo a transformation where it would be changed to an acceptable medium of exchange. This would involve standardising its weight and measure to specifications demanded by the market. Whether this occurs directly by a mine, or by a third party is inconsequential to the analysis. ${ }^{7}$ It would then be issued, not freely, but only at a profit, to the general population. Hence, actual supply of the gold currency in use would only come to use through the free-market demands of the individuals.

Relative price changes (commonly gauged by the CPI or PPI) within the economy would thus not be affected adversely by government intervention, as is possible with fiat currency, but would fluctuate concurrent with market demands. Any general inflationary pressure on prices that affects the economy would be the result of its own demands, and would not necessarily trigger the trade cycle.

7 As pointed out originally by Say, and expanded on by Rothbard (1994, 29), banking originated with two distinct functions, depositor warehousing, and financial intermediation. It was only the advent of fractional reserve banking that combined these two roles of credit creation and the banking system into one. 
Nor would international monetary relations be adversely affected. The market contains a self-regulating mechanism that would naturally compensate for the resultant monetary gold flows. For instance, a net-exporter economy would see an influx of monetary gold enter. This may pose general inflationary pressures on the economy, but as was noted above, as it is freemarket oriented, would not cause any undo suffering among the market's entrepreneurs. On the other hand, a net-importer economy would see a general exit of its monetary gold stocks as it purchases more than it is able to produce. As monetary gold exits the country, the relative purchasing power of the economy would decline, stimulating exports to its now relatively more wealthy counterparts. These stabilising factors would eliminate large trade deficits as imbalances would be corrected by the inflow/outflow mechanism.

Fiat money also serves this role, in much the same manner. In fact, we can find no discernible differences between the functioning of gold money, and fiat money in the economy in this respect. As long as the medium of exchange is commonly accepted, it makes no significant difference what is exchanged. However, the key to this section is the term "commonly accepted", for it is exactly gold's longevity as a store of value that allows it to excel in this role over a fiat counterpart.

\section{Monetary gold as a store of value}

The graveyard of currencies is littered with the notes and bills of fiat monies gone bust. The ashes of these expired, bankrupt currencies have all been caused, without exception, not from a money no longer being suitable as a medium of exchange, but as a store of value. Kvasnička fails to touch on this important point, but it becomes an important one when viewing his conclusion that an immediate return to the gold standard is unlikely due to possible price instability.

A currency serves two purposes, one of which has throughout history proven to be its falling. The illusive store of value has always been perverted in favour of a fiat, or fractional, alternative 
that inevitably ends in disaster. If we take the position, as Kvasnička surely does, that even if ever so slowly the purchasing power of all fiat monies are being diminished, should an action not be taken to correct it?

Hayek $(1976,13)$ tells one particularly fitting story of his personal experience with the diminishing value of fiat currencies:

This decay was recently brought home to me by a curious incident: I found in a drawer of my desk a British penny dated 1863 which a short 12 years ago, that is, when it was exactly a hundred years old, I had received as change from a London bus conductor and had taken back to Germany to show my students what long-run monetary stability meant. I believe they were duly impressed. But they would laugh in my face if I now mentioned Britain as an instance of monetary stability.

If short-term price stability is a sacrifice for long-term viability, is this not a positive trade off? The answer is, we don't know. We can know what we as individuals prefer, but not that of others. We can however note that true cost is the alternative foregone for something, the opportunity cost. Viewed in this manner, potential short-term volatility may be a good trade off for long-term sustainability. In comparing commodity and fiat money, it may be instructive to look at their volatility extremes. When a fiat currency suffers from extreme volatility, the result may possibly be severe, or hyper, inflation and eventual default. In distinction, a commodity currency may suffer value volatility as well, but this is generally constrained by hard, physical supply factors with the extreme results being considerably less-likely, and destructive.

In light of this, the faster a currency can revert to a hard standard, restraining future supply-side abuses to its purchasing power, the faster the economy can be assured that the currency will continue to function in its role of a medium of exchange. 


\section{$\mathrm{V}$ \\ CONCLUSION}

The largest issue we find with Kvasnička's critique of gold's suitability is the «straw-man» argument he creates. Even if it could be theoretically shown that that the gold-standard was a poor option for adoption by smaller economies, this would not refute the true Austrian, or free-market, stance. While almost all Austrians advocate a commodity standard, and most would consider this de facto as gold, none would agree that this standard should be time invariant. A commodity standard's strength lies not in its selection as an optimal commodity to exchange at any given time, but in being the best to exchange at a particular point in time.

Hülsmann $(2003,59)$ sums the problem nicely, «[p]roblems start as soon as any type of money enjoys the legal privilege of being the "standard" money, and thus, is immunised from competition. We have shown that competition is essential for the smooth replacement of one (technologically inferior) money by other commodity monies.» The argument is not to adopt a gold standard, but to elect a commodity standard as the market demands, and to recognise this is subject to change as market conditions warrant. ${ }^{8}$

The separation of money creation and political forces is difficult, if not impossible, as Barro $(1979,13)$ notes, «[t]his separation can only be partial since, at the level of choice of a monetary regime, it is clear that the determination of money and prices cannot be divorced from the political process. The possibility for alterations in the underlying regime is exhibited by the gradual erosion of the international gold standard since 1914, and especially since the 1930s.» We know this separation via a non-market entity is the more optimal alternative. Kvasnicka (52) thinks that to achieve this objective of reestablishing the gold standard "would probably have to involve the collective action of many countries of great economic power.» This "cure» still does not erase the root issue at hand, the removal of a non-market entity from the money control

8 The somewhat paradoxical conclusion is that there could possibly occur a time when the gold-standard fails to be the gold-standard of the monetary system. 
process. In fact, Hayek $(1976,15)$ would point out that a collaboration could prove damaging towards a commodity standard:

I am fairly convinced that any attempt now to re-instate the gold standard by international agreement would break down within a short time and merely discredit the ideal of an international gold standard even longer. Without the conviction of the public at large that certain immediately painful measures are occasionally necessary to preserve reasonable stability, we cannot hope that any authority which has power to determine the quantity of money will no long resist the pressure for, or the seduction of, cheap money. [emphasis added]

When Austrians defend the gold standard, what they are really defending is a person's right to choose their own affairs. The use of a money is not a set decision, but one that is subject to change as market conditions dictate. Kvasnička is right to question the prevailing free-market opinion concerning monetary gold, and does a great justice in demonstrating that historical success is not alone to be proof that a gold-standard is the optimal money for the future, or for all economies. However, as has been demonstrated, theory alone can justify what the optimal free-market monetary stance should be; a commodity standard based on a market chosen and agreed upon medium. Given that political influence erases this right of choice, we can see that the choice of money is not just a monetary concern, but one of personal liberty. To this end, we can only sum up with Hülsmann's $(2003,57)$ enlightening and succinct note that $« . .$. the flight from money is a great force of liberty.» Indeed, in monetary matters, it may be our greatest liberty.

\section{BIBLIOGRAPHICAL REFERENCES}

Barro, Robert, J., (1979) «Money and the Price Level Under the Gold Standard.» The Economic Journal, vol. 89, n.. 353 (March): 13-33.

Dowd, KeviN, (1988) «Automatic Stabilizing Mechanisms Under Free Banking.» Cato Journal, vol. 7, n.ํㅡ 3 (Winter): 643-659. 
Research Division of the Federal Reserve Bank of St. Louis. (2008) Monetary Trends. (March), http:/ / research.stlouisfed.org. Garrison, Roger, W., (1992) The Gold Standard: Perspectives in the Austrian School, ed. Llewellyn H. Rockwell Jr. Lexington, Mass: D.C. Heath.

- (1996) «Central Banking, Free Banking, and Financial Crises.» The Review of Austrian Economics, vol. 9, n. 2: 109-127.

HAYEK, F.A., (1943) «A Commodity Reserve Currency» reprinted in Individualism and Economic Order. Chicago, IL: University of Chicago Press.

- (1976). Choice in Currency: A Way to Stop Inflation. London: The Institute of Economic Affairs.

Hülsmann, Jörg Guido, (2003) «Optimal Monetary Policy.» The Quarterly Journal of Austrian Economics, vol. 6, n.. 4 (Winter): 37-60.

KVASNiČKA, Michal, (2007) «Stability of Gold Standard and its Selected Consequences.» Procesos de Mercado: Revista Europea de Economía Política, vol. IV, n.․ 2 (otoño): 33-56.

Menger, CARL, (1892) «On the Origins of Money.»Economic Journal, vol. 2; 239-255.

- (2007). Principles of Economics. Auburn, AL: Ludwig von Mises Institute.

RADFORD, R.A., (1945). The Economic Organization of a P.O.W. Camp. Economica (12)48: 189-201.

Rothbard Murray, N., (1994) «The Case Against the Fed.» Auburn, AL: Ludwig von Mises Institute.

- (2004). Man, Economy, and State: A Treatise on Economic Principles. Auburn, AL: Ludwig von Mises Institute. 